\title{
Grain Refinement of Al-Mg-Sc Alloy by Ultrasonic Treatment
}

\author{
N. Q. Tuan*, H. Puga, J. Barbosa, and A. M. P. Pinto \\ University of Minho, CT2M - Centre for Mechanical and Materials Technologies, Azurém \\ 4800-058 Guimarães, Portugal
}

(received date: 2 April 2014 / accepted date: 13 May 2012)

\begin{abstract}
In foundry practice, ultrasonic treatment has been used as an efficient technique to achieve grain refinement in aluminium and magnesium alloys. This article shows the strong effect of pouring temperature and ultrasonic treatment at various temperatures on the grain refinement of $\mathrm{Al}-1 \mathrm{wt} \% \mathrm{Mg}-0.3 \mathrm{wt} \% \mathrm{Sc}$ alloy. Without ultrasonic treatment, a fine grain structure was obtained at the pouring temperature of $700{ }^{\circ} \mathrm{C}$. The average grain size sharply decreases from $487 \pm 20$ to $103 \pm 2 \mu \mathrm{m}$ when the pouring temperature decreases from 800 to $700{ }^{\circ} \mathrm{C}$. Ultrasonic vibration proved to be a potential grain refinement technique with a wide range of pouring temperature. A microstructure with very fine and homogeneous grains was obtained by applying ultrasonic treatment to the melt at the temperature range between 700 and $740{ }^{\circ} \mathrm{C}$, before pouring. Cavitation-enhanced heterogeneous nucleation is the mechanism proposed to explain grain refinement by ultrasound in this alloy. Moreover, ultrasonic treatment of the melt was found to lead to cast samples with hardness values similar to those obtained in samples submitted to precipitation hardening, suggesting that ultrasonic treatment can avoid carrying out heat treatment of cast parts.
\end{abstract}

Keywords: Alloys, casting, grain refinement, pouring temperature, ultrasonics

\section{INTRODUCTION}

In foundry practice of aluminium alloys, several processes have been applied to achieve a fine, equiaxed and uniform grain microstructure. The three major mechanisms for grain refinement during solidification process are heterogeneous nucleation, restricting the grain growth and breaking the solidified crystals. Grain refinement with inoculation of AlTi or Al-Ti-B master alloys is widely applied in industry [1-4]. In this method, $\mathrm{TiAl}_{3}$ and $\mathrm{TiB}_{2}$ particles are formed in the melt and act as heterogeneous nucleation sites for $\alpha$-Al grains. However, only $1 \%$ of the refiner particles are active for nucleation of solid grain $[1,3]$. The rest of them contaminate the casting alloy and have detrimental effects on the final microstructure and mechanical properties. Some other techniques have been applied for grain refinement, such as mechanical stirring, electromagnetic stirring [5], low-temperature casting [6], and intensive melt shearing above liquidus temperature $[7,8]$. However those techniques are time consuming, can promote low fluidity and are high costly.

During the last years an effort has been done to develop reliable ultrasonic techniques to control the microstructure of several engineering alloys, with particular emphasis to $\mathrm{Al}$ and $\mathrm{Mg}$ based ones, to overtake the problems associated to

*Corresponding author: quoctuan1884@gmail.com CKIM and Springer traditional refinement techniques. Khalifa et al. [9] and Jian et al. [10] demonstrated that it is possible to obtain non dendritic and globular grains of primary $\alpha-\mathrm{Al}$ phase smaller than $100 \mu \mathrm{m}$ by supplying acoustic energy to molten AlSi7Mg, isothermally and during solidification, respectively. Ultrasonic vibration can also be used to refine hypereutectic Al-Si alloys, as demonstrated by Feng et al. [11], who obtained equiaxed, $\alpha$-Al crystals of around $40 \mu \mathrm{m}$ and homogeneously distributed primary Si phase with average size of $180 \mu \mathrm{m}$ in AlSi23 alloy.

Three mechanisms have been proposed to explain for grain refinement by ultrasonic treatment: (1) cavitation-enhanced heterogeneous nucleation; (2) cavitation-induced dendrite fragmentation; (3) vibration-stimulated separation of wall crystals. The cavitation-enhanced heterogeneous nucleation was explained through three mechanisms. The first mechanism is based on the promotion of the wetting behaviour of second phase particles with the melt due to cavitation bubbles collapse. When ultrasonic vibration was applied into the melt, a large number of cavitation bubbles were formed and dispersed in the whole of the melt [12]. The collapse of cavitation bubbles in the vicinity of second phase particles leads to produce locally high temperature, pressures and melt flows [13]. The pressures pulse promotes filling of the cracks (capillaries) on the surface of second phase particles by the melt and improves the wetting of those particles with the melt [14]. According to Easton and StJohn [15], the higher wettability of substrates with the melt leads to the smaller free energy 
barrier for nucleation even at relatively low undercooling. As a consequence, these substrates will acts as effective nucleation sites and enhance the nucleation [13]. The second mechanism is based on the pressure pulse melting point where the pressure pulse generated from the cavitation bubbles collapse conducts the increasing of melting point according to the Clausius-Clapeyron Eq $[13,16]$. Consequently, the localized undercooling occurs that leads to promote nucleation throughout the melt.

The third mechanism explained that the expansion of gas inside the cavitation bubbles leads to increase the bubble size and decrease the bubble temperature [16,17]. This phenomenon resulted in undercooling of the melt and form nuclei on the surface of bubbles. When these bubbles collapsed, a significant number of nuclei were produced into the melt and promoted heterogeneous nucleation in the melt.

In the cavitation-induced dendrite fragmentation mechanism, fragmentation of dendrites occurred by the shock waves that were generated from bubbles collapse. These fragments were distributed throughout the melt by acoustic streaming which leads to increase the number of solidification sites $[13,18,19]$. According to the vibration-stimulated separation of wall crystals mechanism, the ultrasonic treatment increased the wettability of the mould wall with the melt that resulted in the promotion of nucleation on the mould wall [20]. The local shaking and/or shearing during ultrasonic vibration conducted the separation of the nuclei from the mould wall into the whole of the melt. Due to this trend, the number of nucleation sites was increased and hence grain refinement was obtained.

It is important to notice that until now the capability of ultrasound as microstructure refinement technique of metallic alloys has been evaluated for a very narrow range of alloys. Most of the studies have been directed to magnesium alloys [21-25] and aluminium-silicon alloys [9-11,17,26-29]. Besides, in foundry practice cast alloys must not be poured at low temperature because consequent low fluidity often leads to premature solidification, cold shuts and incomplete castings. On the other hand, high pouring temperatures usually promote grain coarsening, oxide formation, and gas porosity. Ultrasonic treatment is a potential process to obtain grain refinement within a wide temperature range, decreasing or even eliminating the traditional defects associated to high or low refining and pouring temperatures.

Al-Mg-Sc alloys have received a lot of attention due to their excellent mechanical behavior [30-32]. However, there are no available studies concerning grain refinement of these alloys. In the present work, the effect of ultrasonic treatment on grain refinement of $\mathrm{Al}-1 \mathrm{wt} \% \mathrm{Mg}-0.3 \mathrm{wt} \% \mathrm{Sc}$ alloy at a wide range of pouring temperatures was evaluated. The microstructures of $\mathrm{Al}-1 \mathrm{wt} \% \mathrm{Mg}-0.3 \mathrm{wt} \% \mathrm{Sc}$ alloy at various pouring temperatures without and with ultrasonic treatment were studied. The mechanism of grain refinement was proposed and deeply understood. The age hardening behaviour of the alloy without and with ultrasonic treatment was investigated.

\section{EXPERIMENTAL PROCEDURE}

\subsection{Experimental set-up}

The experimental set-up (Fig. 1) used in this work consisted of a novel MMM (Multi-frequency, Multimode, Modulated technology) ultrasonic power supply unit, a high power ultrasonic converter $(1200 \mathrm{~W})$, a $30 \mathrm{~mm}$ diameter and $150 \mathrm{~mm}$ long acoustic waveguide and the acoustic load itself which consists on a $20 \mathrm{~mm}$ diameter and $75 \mathrm{~mm}$ long $\mathrm{Nb}$ acoustic radiator and the melt.

\subsection{Materials and melting}

Melting stocks of $\mathrm{Al}-1 \mathrm{Mg}-0.3 \mathrm{Sc}$ (wt $\%$ ) consisted of commercially pure $\mathrm{Al}$ ( $99.83 \mathrm{wt} \%$ purity), $\mathrm{Al}-2 \mathrm{wt} \% \mathrm{Sc}$ and $\mathrm{Al}-20 \mathrm{wt} \% \mathrm{Mg}$ master alloys. Suitable masses of these starting materials were melted in a $\mathrm{SiC}$ crucible, using an electrical resistance furnace. For each alloy, pure $\mathrm{Al}$ was firstly melted at $800 \pm 5^{\circ} \mathrm{C}$. Then the master alloys were added into the melt. The melt was kept at this temperature for 30 minutes and stirred with an alumina rod to ensure homogeneity. The melt was cooled down to different temperatures ranging from $800 \pm 5^{\circ} \mathrm{C}$ to $700 \pm 5^{\circ} \mathrm{C}$ and the sonotrode was preheating to avoid a drop in temperature of the melt when applying ultrasonic vibration. Ultrasonic frequency of $20.3 \pm 0.25 \mathrm{kHz}$ at electric power of $30 \%$ for $30 \mathrm{~s}$ was applied for each processing condition. After ultrasonic treatment, the molten alloy was poured into a copper mould and immediately cooled to ambient temperature by immersion in water. Cast samples were cylinders with $16 \mathrm{~mm}$ diameter and $80 \mathrm{~mm}$ long. For the sake of comparison experiments were also carried out without ultrasonic vibration, using the same operation parameters.

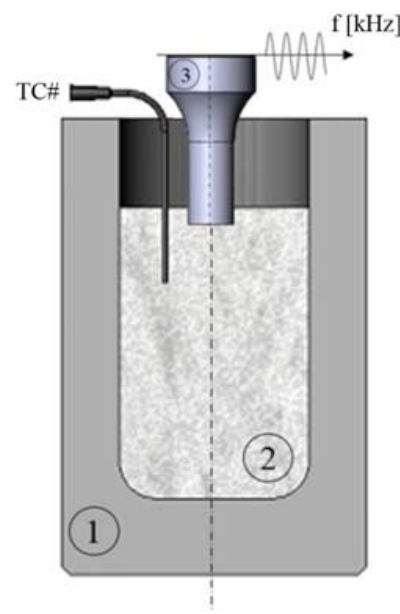

(a)

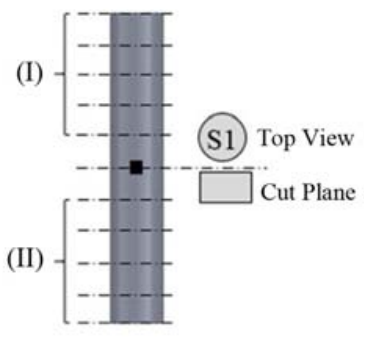

(b)
Fig. 1. (a) Schematic representation of the experimental setup used in the experiments ((1) SiC Crucible, (2) the melt and (3) Acoustic radiator); (b) position of the analysed sections on the sample. 


\subsection{Microstructural characterization}

Samples for microstructural characterization were taken from each cast sample by sectioning them perpendicularly to its longitudinal axis (S1 in Fig. 1(b)). The samples were ground with $\mathrm{SiC}$ paper, polished down using non-crystallizing colloidal silica suspension and anodised at a voltage of $30 \mathrm{~V}$ in a $2.5 \%$ aqueous solution of flouroboric acid $\left(\mathrm{HBF}_{4}\right)$ to reveal grain size. The overall microstructure morphology was analysed by optical microscopy using a Leica DM $2500 \mathrm{M}$ and Image-Pro Plus software was used to quantify the average grain size and grain size distribution.

In order to evaluate the mechanical properties, isothermal aging of the alloys with and without ultrasonic treatment was carried out. Samples for this step were taken from section I and II (Fig. 1(b)). The as-cast alloys were aged at $300{ }^{\circ} \mathrm{C}$ for times ranging from 1 hour to 7 days. Vickers hardness was used to monitor the hardening behaviour. Vickers hardness measurements were performed at room temperature using $30 \mathrm{~kg}$ load and $20 \mathrm{~s}$ dwell time. Eight measurements were performed on each sample.

\section{RESULTS AND DISCUSSION}

\subsection{Effect of pouring temperature on grain size of Al- $1 \mathrm{Mg}-0.3 \mathrm{Sc}$ alloy without ultrasonic treatment}

Figure 2 shows the optical micrographs of as-cast Al$1 \mathrm{Mg}-0.3 \mathrm{Sc}$ alloys without ultrasonic treatment poured at 800 and $770{ }^{\circ} \mathrm{C} \pm 5^{\circ} \mathrm{C}$. The microstructure exhibits columnar zones (present in the centre of the samples) with elongated grains and dendritic features and the outer chill zones (present in the border of samples) with finer and more equiaxed grains. The average grain size of $\mathrm{Al}-1 \mathrm{Mg}-0.3 \mathrm{Sc}$ samples poured at

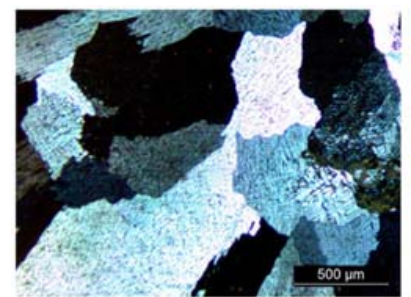

(a)

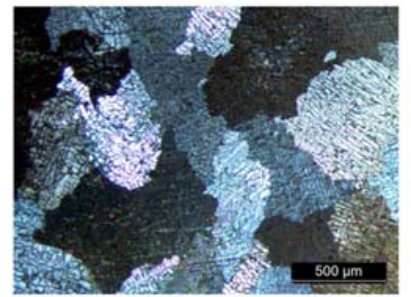

(c)

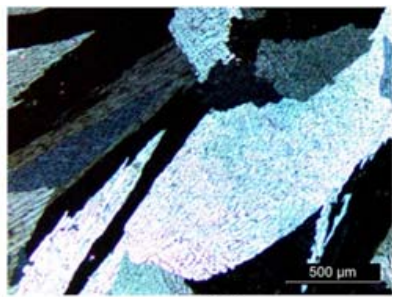

(b)

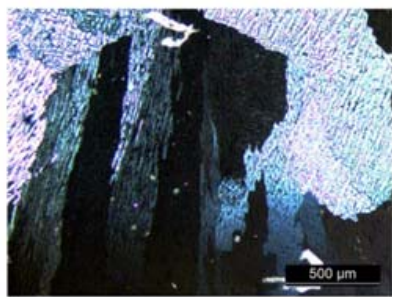

(d)
Fig. 2. Optical micrographs of Al-1Mg-0.3Sc alloy cast at pouring temperatures: (a-b) $800^{\circ} \mathrm{C}$, (c-d) $770{ }^{\circ} \mathrm{C}$ : (a), (c) in the border of samples; (b), (d) in the centre of samples.

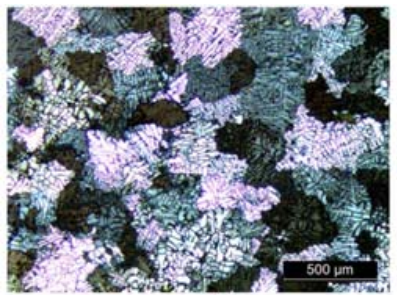

(a)

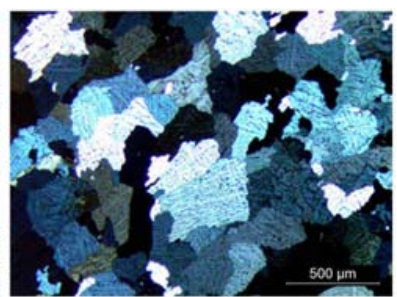

(b)

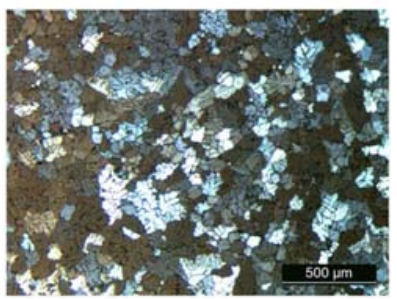

(c)

Fig. 3. Optical micrographs of $\mathrm{Al}-1 \mathrm{Mg}-0.3 \mathrm{Sc}$ alloy cast at pouring temperatures: (a) $740{ }^{\circ} \mathrm{C}$, (b) $720 \mathrm{C}$, (c) $700^{\circ} \mathrm{C}$.

800 and $770{ }^{\circ} \mathrm{C} \pm 5{ }^{\circ} \mathrm{C}$ are $487 \pm 20$ and $394 \pm 14 \mu \mathrm{m}$. The different morphology of coarse grains in the different zones can be explained by the different solidification rate and interfacial temperature gradient [33]. In the chill zone, under the large supercooling that occurs as soon as the molten alloy contacts the cold mould wall a large number of nuclei forms and grow as equiaxed shaped grains. After pouring, the temperature gradient at the mould walls decreases and the grains in the chill zone grow dendritically side by side in the direction of the heat flow which is perpendicular to the mould walls. They stop growing when they meet grains growing out from the opposite wall. This process leads to the formation of elongated grains and creates the columnar zone.

Figure 3 shows the optical micrographs of as-cast Al-1Mg$0.3 \mathrm{Sc}$ alloys without ultrasonic treatment poured at 740,720 and $700^{\circ} \mathrm{C} \pm 5^{\circ} \mathrm{C}$. It is evident that grain size gradually decreases with decreasing of pouring temperature. The average grain size of Al-1Mg-0.3Sc samples poured at 740,720 , and $700{ }^{\circ} \mathrm{C}$ are at $269 \pm 8,197 \pm 5$ and $103 \pm 2 \mu \mathrm{m}$, respectively. It is evident to conclude that the pouring temperature has a strong influence on the grain size of the Al-1Mg-0.3Sc alloy.

The grain size distribution of $\mathrm{Al}-1 \mathrm{Mg}-0.3 \mathrm{Sc}$ samples poured at $800,770,740,720$ and $700 \pm 5^{\circ} \mathrm{C}$ is illustrated in Fig. 4. The grain size of those samples is within the range of 200$1000,200-800,100-500,50-400$, and 50-270 $\mu \mathrm{m}$, respectively. It is evident that the most fine and uniform equiaxed grains were achieved on the sample cast at $700{ }^{\circ} \mathrm{C}$.

According to Murty et. al.[34], the mechanism of grain refinement is still not clear and considerable controversy still exists between researchers. The solute paradigm proposed by Johnsson et. al. [35] could be applied to explain the grain refinement mechanism for those results. Li et al. [36] indicated that the high affinity of $\mathrm{Mg}$ with oxygen leads to the forma- 


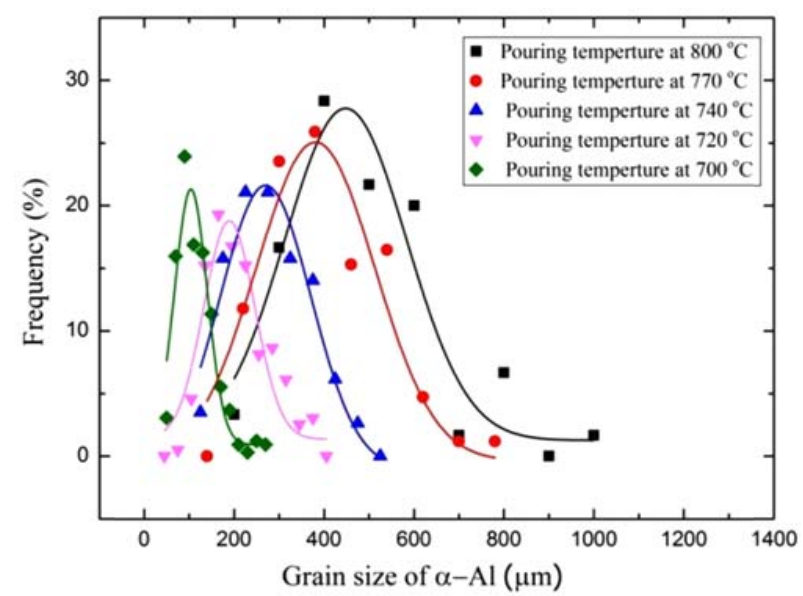

Fig. 4. Grain size distribution of Al-1Mg-0.3Sc cast samples for different pouring temperatures.

tion of $\mathrm{MgAl}_{2} \mathrm{O}_{4}$ oxide in the melt. The $\mathrm{MgAl}_{2} \mathrm{O}_{4}$ oxide has a perfect lattice matching with $\alpha-\mathrm{Al}$ at the $\{111\}$ plane that promotes high tendency to heterogeneous nucleation. Johnsson's hypothesis suggested that the nucleant particles and segregating elements are the two important factors to control grain refinement. Solute elements like $\mathrm{Sc}, \mathrm{Mg}, \mathrm{Si}, \mathrm{Cu}$ and $\mathrm{Fe}$ segregate to the nucleant/melt interface and restrict the growth of dendrites, so there is more time for nucleation to occur $[34,35]$. Besides, segregating elements would lead to constitutional under-cooling in front of the interface and facilitates nucleation for $\alpha-\mathrm{Al}$ grains. The nucleant particles in this case could be $\mathrm{MgAl}_{2} \mathrm{O}_{4}$ oxide or impurity particles. Segregating $\mathrm{Sc}$ can lead to form $\mathrm{Al}_{3} \mathrm{Sc}$. $\mathrm{Al}_{3} \mathrm{Sc}$ with $\mathrm{Ll}_{2}$ structure has a small lattice parameter mismatch and fully coherent with the $\alpha-\mathrm{Al}$ at elevated temperatures that can acts as a potential nucleation site for $\alpha$-Al grains [37-39]. Moreover, in the ternary or higher-order systems, the eutectic composition depends on the alloying elements. According to Alexander Pisch et al. [40], the eutectic composition of Sc decreases with increasing $\mathrm{Mg}$ content in the $\mathrm{Al}-\mathrm{Mg}-\mathrm{Sc}$ alloy. This characteristic facilitates the formation of $\mathrm{Al}_{3} \mathrm{Sc}$.

At high pouring temperature, the melt is quite homogeneous that results in a decrease in the segregating potency of solute elements. The constitutional under-cooling in front of the nucleant/melt interface did not occur and $\mathrm{Al}_{3} \mathrm{Sc}$ was not formed. It leads to reduce the nucleant potency. As a consequence, very coarse grains were observed in $\mathrm{Al}-1 \mathrm{Mg}-0.3 \mathrm{Sc}$ alloy cast at high temperature. A lower pouring temperature conducts to a higher segregating potency and nucleant potency that result in a better refining effect.

\subsection{Effect of ultrasonic treatment at various temperatures on grain size of $\mathrm{Al}-1 \mathrm{Mg}-\mathbf{0 . 3 S c}$ alloy \\ Figures 5 and 6 show the optical micrographs and the grain size}

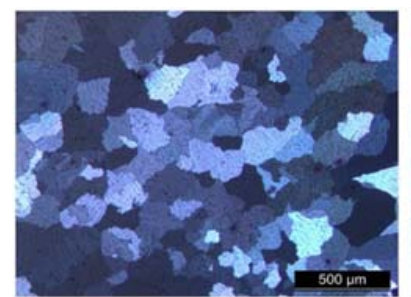

(a)

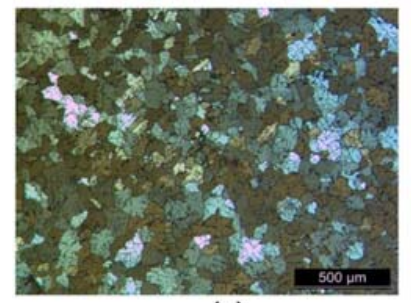

(c)

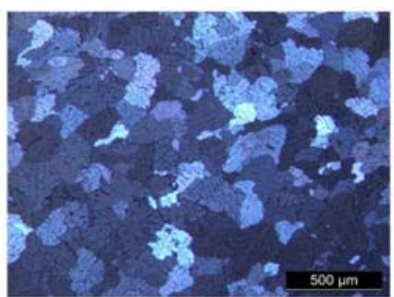

(b)

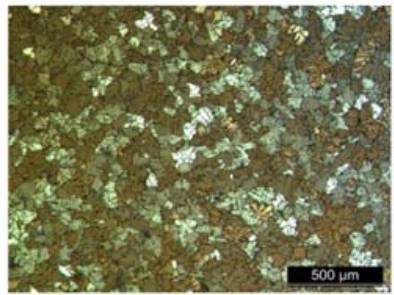

(d)

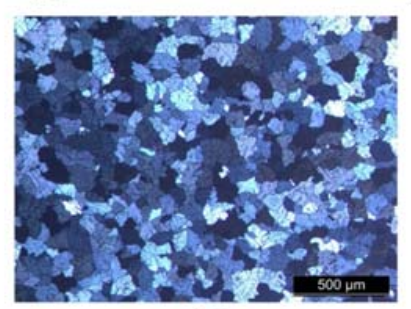

(e)

Fig. 5. Optical micrographs of $\mathrm{Al}-1 \mathrm{Mg}-0.3 \mathrm{Sc}$ alloy ultrasonic treated at different temperatures: (a) $800^{\circ} \mathrm{C}$, (b) $770{ }^{\circ} \mathrm{C}$, (c) $740^{\circ} \mathrm{C}$, (d) $720^{\circ} \mathrm{C}$, (e) $700^{\circ} \mathrm{C}$.

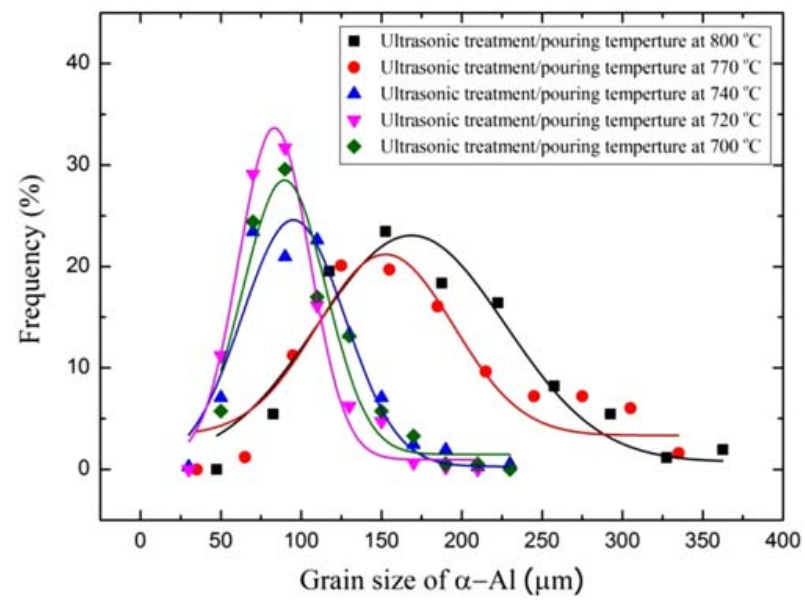

Fig. 6. Grain size distribution of $\mathrm{Al}-1 \mathrm{Mg}-0.3 \mathrm{Sc}$ samples ultrasonic treated at different temperatures.

distribution of $\mathrm{Al}-1 \mathrm{Mg}-0.3 \mathrm{Sc}$ cast samples with ultrasonic treatment at the temperatures of $800,770,740,720$, and $700 \pm 5^{\circ} \mathrm{C}$. It is obvious that the impact of ultrasonic treatment on grain refinement depends on the treatment temperature. The influence of ultrasonic treatment on grain refinement is most effective 


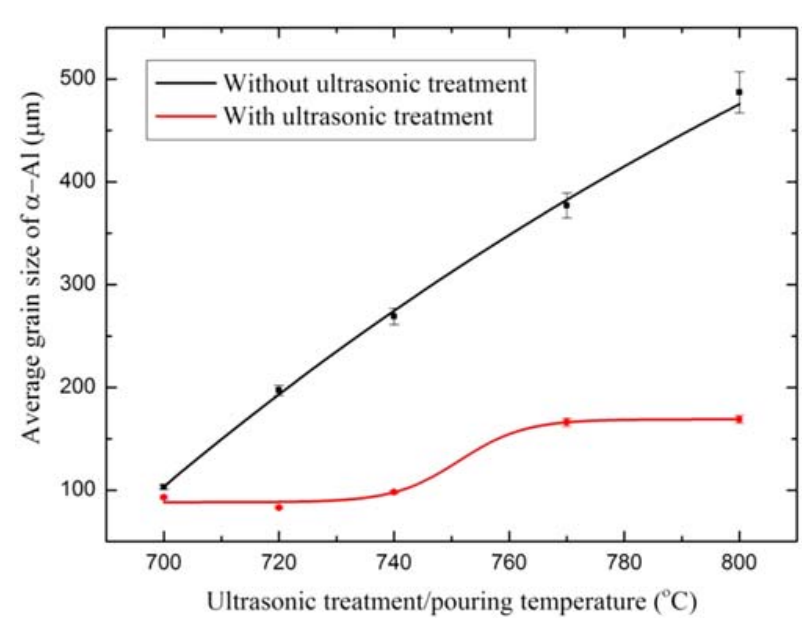

Fig. 7. Effect of ultrasonic treatment on the average grain size of Al$1 \mathrm{Mg}-0.3 \mathrm{Sc}$ alloys.

within the temperature range of $700-740{ }^{\circ} \mathrm{C}$. The average grain size of cast samples is $98 \pm 2,83 \pm 1,93 \pm 2 \mu \mathrm{m}$ for 740,720 , and $700{ }^{\circ} \mathrm{C}$ US treatment temperatures, respectively. When the alloy was treated by ultrasonic vibration at 770 and $800^{\circ} \mathrm{C}$, the grains tended to be larger, with average size of $166 \pm 4$ and $169 \pm 4 \mu \mathrm{m}$, respectively. At the temperature of $720^{\circ} \mathrm{C}$, the grains are finer and more uniform than at any other treatment temperature. The quantitative results of the average grain size of $\mathrm{Al}-1 \mathrm{Mg}-0.3 \mathrm{Sc}$ alloys are summarized and presented in Fig. 7 to compare the grain size of alloys with and without ultrasonic treatment. The strong refinement effect of ultrasound is quite clear, especially if the treatment is conducted within the temperature range $700-740^{\circ} \mathrm{C}$. Fig. 8 shows the grain size distribution of the most refined samples with and without ultrasonic treatment. It is evident that ultrasonic vibration not only decreases the average grain size but also homogenizes

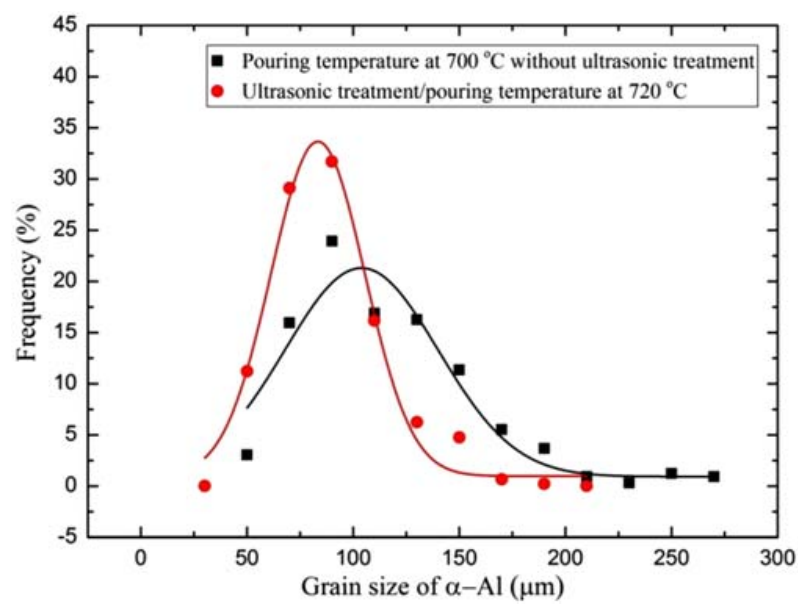

Fig. 8. Effect of ultrasonic treatment temperature on grain size distribution of $\mathrm{Al}-1 \mathrm{Mg}-0.3 \mathrm{Sc}$ cast samples. grain size distribution, as can be inferred by the higher frequency of grains with less than $100 \mathrm{~mm}$. These results suggest that ultrasonic treatment can be applied to foundry practice of the $\mathrm{Al}-1 \mathrm{Mg}-0.3 \mathrm{Sc}$ alloy at a wide range of temperatures ensuring both fluidity of the melt and grain refinement.

We propose that cavitation-enhanced heterogeneous nucleation is the main mechanism of grain refinement by ultrasonic treatment in Al- $1 \mathrm{Mg}-0.3 \mathrm{Sc}$ alloy. When the ultrasonic treatment was applied directly into the melt, a large number of cavitation bubbles were formed throughout the melt. These cavitation bubbles grow and the bubbles temperature decreases due to the expansion of the gas inside them. At critical size of bubbles, they will collapse and generate the pressure pulse. The increase of the local pressure in the melt leads to transiently increase of the melting point of the alloy according to the Clausius-Clapeyron Eq. The decrease of bubble temperature and the increase of melting point lead to high localized undercooling at the bubble- melt interface. As a consequence, a large number of nuclei formed at the surface of existing bubbles. These bubbles will collapse and disperse nuclei into the melt. Through acoustic streaming, the nuclei are homogeneously distributed throughout the melt. Morever, the cavitation phenomenon cleans the surfaces of nuclei, improves their wettability and consequently increase the nucleant potency.

High US treatment temperatures will shorten the life time of cavitation bubbles and decrease undercooling in the melt. Therefore, the number of nuclei formed in the melt will decrease which results in less grain refinement. This mechanism explains the increase in average grain size when the US treatment temperature increases from 720 to $800^{\circ} \mathrm{C}$. The slightly higher grain size of the alloy treated at $700^{\circ} \mathrm{C}$ in comparison with $720^{\circ} \mathrm{C}$ can be explained by a decrease in melt fluidity. The lower fluidity of the melt reduces the dispersion of nuclei that results in less grain refinement.

\subsection{Age hardening behaviour}

The time dependence of age hardening at $300{ }^{\circ} \mathrm{C}$ of Al$1 \mathrm{Mg}-0.3 \mathrm{Sc}$ alloys cast at $700^{\circ} \mathrm{C}$ without ultrasonic treatment and at $720^{\circ} \mathrm{C}$ with ultrasonic treatment are shown in Fig. 9. For the as-cast alloy without US treatment, Sc exists in supersaturated solid solution with $\mathrm{Al}$ and $\mathrm{Mg}$. After isothermal aging the hardness values varied with the aging time due to the formation and development of $\mathrm{Al}_{3} \mathrm{Sc}$ precipitates. The hardness of the alloy increase and reach a maximum value of $86 \mathrm{HV}$ (aging peak) when the $\mathrm{Al}_{3} \mathrm{Sc}$ precipitates nucleate from supersaturated solid solution and grow. The Al-1Mg-0.3Sc alloy without ultrasonic treatment reaches the aging peak after $5 \mathrm{~h}$ at $300^{\circ} \mathrm{C}$. After 7 days aging, a slightly softening due to over-aging was observed. The hardness of the ultrasonic treated $\mathrm{Al}-1 \mathrm{Mg}-0.3 \mathrm{Sc}$ cast sample was $82 \mathrm{HV}$, which is very close to that corresponding to the aging peak of $\mathrm{Al}-1 \mathrm{Mg}$ $0.3 \mathrm{Sc}$ alloy without ultrasonic treatment aged at $300^{\circ} \mathrm{C}$. Thus, by applying ultrasonic vibration to the melt, heat treat- 


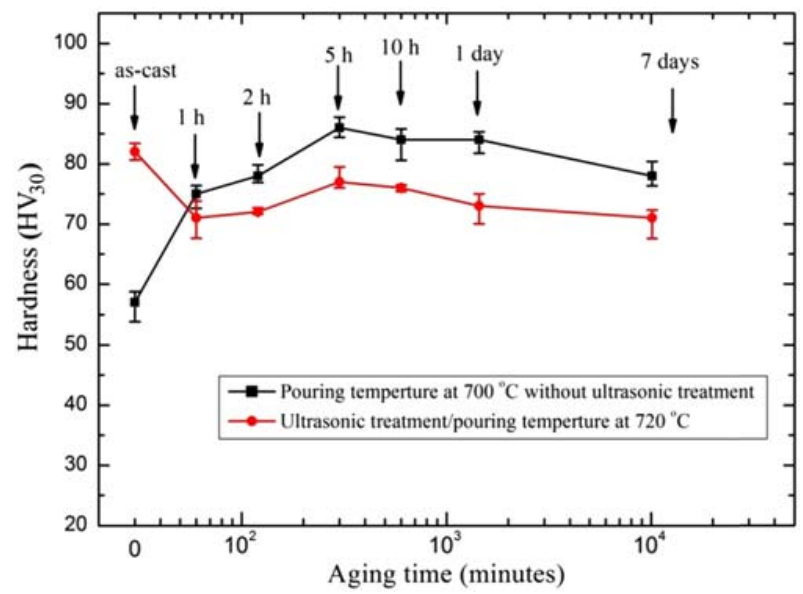

Fig. 9. Isothermal aging curve at $300^{\circ} \mathrm{C}$ of $\mathrm{Al}-1 \mathrm{Mg}-0.3 \mathrm{Sc}$ alloys cast at $700{ }^{\circ} \mathrm{C}$ without ultrasonic treatment and at $720^{\circ} \mathrm{C}$ with ultrasonic treatment.

ment of the cast samples for strength enhancement can perhaps be avoided.

\section{CONCLUSIONS}

The following conclusions can be drawn from this study:

(1) The microstructure of as-cast Al- $1 \mathrm{Mg}-0.3 \mathrm{Sc}$ alloy depends on the pouring temperature. The average grain size of this alloy sharply decreases from $487 \pm 20$ to $103 \pm 2 \mu \mathrm{m}$ when the pouring temperature decreases from 800 to $700{ }^{\circ} \mathrm{C}$.

(2) Ultrasonic vibration proved to be a potential grain refinement technique of Al-1Mg-0.3Sc. Significant grain refinement was obtained by applying ultrasonic treatment within the temperature range from 700 to $740{ }^{\circ} \mathrm{C}$. This fact makes more flexible to decide the pouring temperature in the foundry practice of this kind of alloy. The best grain refinement and uniform grain size are obtained by ultrasonic treatment at $720^{\circ} \mathrm{C}$.

(3) Grain refinement of Al- $1 \mathrm{Mg}-0.3 \mathrm{Sc}$ alloy by ultrasonic treatment can be explained by the cavitation-enhanced heterogeneous nucleation mechanism.

(4) The hardness of the ultrasonic treated Al- $1 \mathrm{Mg}-0.3 \mathrm{Sc}$ cast sample is very close to the hardness value at aging peak of Al-1Mg-0.3Sc alloy aged at $300{ }^{\circ} \mathrm{C}$, without ultrasonic treatment. The strength enhancement of $\mathrm{Al}-1 \mathrm{Mg}-0.3 \mathrm{Sc}$ alloy can be obtained by applying ultrasonic treatment and it seems that it can avoid carrying out the traditional aging treatment of this alloy.

\section{ACKNOWLEDGEMENTS}

This research was supported by The Project Bridging The Gap, funded by the Erasmus Mundus External Cooperation Window Programme. Acknowledgements also to the University of Minho, for the provision of research facilities.

\section{REFERENCES}

1. B. Cantor and K. O'Reilly, Solidification and Casting, pp. 213219, Institute of Physics Pub, Bristol, England (2003).

2. A. L. Greer, P. S. Cooper, M. W. Meredith, W. Schneider, P. Schumacher, J. A. Spittle, and A. Tronche, Adv. Eng. Mater. 5, 81 (2003).

3. A. L. Greer, A. M. Bunn, A. Tronche, P. V. Evans, and D. J. Bristow, Acta. Mater. 48, 2823 (2000).

4. P. S. Mohanty and J. E. Gruzleski, Acta. Metall. Mater. 43, 2001 (1995).

5. S. Nafisi, D. Emadi, M. T. Shehata, and R. Ghomashchi, Mater. Sci. Eng. A 432, 71 (2006).

6. K. Xia and G. Tausig, Mater. Sci. Eng. A 246, 1 (1998).

7. R. Haghayeghi, E. J. Zoqui, D. G. Eskin, and H. Bahai, J. Alloy. Compd. 485, 807 (2009).

8. R. Haghayeghi and L. Nastac, Mater. Lett. 65, 3230 (2011).

9. W. Khalifa, Y. Tsunekawa, and M. Okumiya, Int. J. Cast. Metal. Res. 21, 129(2008).

10. X. Jian, H. Xu, T. T. Meek, and Q. Han, Mater. Lett. 59, 190 (2005).

11. H. K. Feng, S. R. Yu, Y. L. Li, and L. Y. Gong, J. Mater. Process. Tech. 208, 330 (2008).

12. H. Xu, Q. Han, and T. T. Meek, Mater. Sci. Eng. A 473, 96 (2008).

13. G. I. Eskin, Ultrasonic Treatment of Light Alloy Melts, pp. 135-166, Gordon and Breach Science, Amsterdam, Netherlands (1998).

14. Y. L. Li, H. K. Feng, F. R. Cao, Y. B. Chen, and L. Y. Gong, Mater. Sci. Eng. A 487, 518 (2008).

15. M. A. Easton and D. H. StJohn, Acta. Mater. 49, 1867 (2001).

16. J. D. Hunt and K. A. Jackson, Jpn. J. Appl. Phys. 37, 254 (1966).

17. X. Jian, T. T. Meek, and Q. Han, Scripta. Mater. 54, 893896 (2006).

18. O. V. Abramov, Ultrasound in Liquid and Solid Metals, pp. 273-326, CRC Press, Florida, U.S.A (1994).

19. G. I. Eskin, Ultrasonics Sonochemistry. 1, S59 (1994).

20. M. Qian, A. Ramirez, and A. Das, Journal of Crystal Growth. 311, 3708 (2009).

21. X. Liu, Y. Osawa, S. Takamori, and T. Mukai, Mater. Sci. Eng. $A$ 487, 120 (2008).

22. D. Gao, Z. Li, Q. Han, and Q. Zhai, Mat. Sci. Eng. A-Struct. A 502, 2 (2009).

23. M. Qian, A. Ramirez, A. Das, and D. H. StJohn, Journal of Crystal Growth 312, 2267 (2010).

24. A. Ramirez, M. Qian, B. Davis, T. Wilks, and D. H. StJohn, Scripta. Mater. 59, 19 (2008).

25. M. Khosro Aghayani, and B. Niroumand, J. Alloy. Compd. 509, 114 (2011).

26. S. Zhang, Y. Zhao, X. Cheng, G. Chen, and Q. Dai, J. Alloy. Compd. 470, 168 (2009).

27. H. Puga, J. Barbosa, S. Costa, S. Ribeiro, A. M. P. Pinto, and M. Prokic, Mater. Sci. Eng. A 560, 589 (2013). 
28. H. Puga, S. Costa, J. Barbosa, S. Ribeiro, and M. Prokic, J. Mater. Process. Tech. 211, 1729 (2011).

29. S. R. Yu, H. K. Feng, Y. L. Li, and L. Y. Gong, J. Alloy. Compd. 484, 360 (2009).

30. E. A. Marquis and D. N. Seidman, Acta. Mater. 53, 4259 (2005).

31. S. Lathabai and P. G. Lloyd, Acta. Mater. 50, 4275 (2002).

32. R. Sawtell and C. Jensen, MTA. 21, 421 (1990).

33. R. Abbaschian, L. Abbaschian, and R. E. Reed-Hill, Physical Metallurgy Principles, 4th ed., pp. 439-442, Cengage Learning, Stamford, USA (2008).

34. B. S. Murty, S. A. Kori, and M. Chakraborty, Int. Mater. Rev.
47, 3 (2002).

35. M. Johnsson, L. Backerud, and G. Sigworth, Metall and Mat Trans A 24, 481 (1993).

36. H. T. Li, Y. Wang, and Z. Fan, Acta. Mater. 60, 1528 (2012).

37. S. Costa, H. Puga, J. Barbosa, and A. M. P. Pinto, Mater. Design. 42, 347 (2012).

38. U. Patakham, J. Kajornchaiyakul, and C. Limmaneevichitr, J. Alloy. Compd. 542, 177 (2012).

39. W. G. Zhang, Y. C. Ye, L. J. He, P. J. Li, X. Feng, and L. S. Novikov, Mater. Sci. Eng. A 578, 35 (2013).

40. A. Pisch, J. Gröbner, and R. Schmid-Fetzer, Mater. Sci. Eng. A 289, 123 (2000). 